\title{
Complications in DIEP Flap Breast Reconstruction After Mastectomy for Breast Cancer: A Prospective Cohort Study Comparing Unilateral and Bilateral Reconstructions
}

\author{
Mark V. Schaverien, MD and Charles E. Butler, MD \\ Department of Plastic Surgery, MD Anderson Cancer Center, Houston, TX
}

The authors should be congratulated for their important contribution to the literature regarding the relative risks of bilateral deep inferior epigastric perforator (DIEP) flap breast reconstruction. A recent meta-analysis by the same group, powered by four case series comparing 400 bilateral DIEP flaps in 200 women with 562 unilateral DIEP flaps found that the risks of total flap failure for bilateral DIEP flap breast reconstruction were greater than the expected doubling, with a risk ratio (RR) of 3.3 per patient (95\% confidence interval [CI] 1.5-7.3; $p=0.003){ }^{1}$

From their systematic review to March 2012, the authors identified a paucity of well-conducted studies that inform whether bilateral DIEP flap breast reconstruction is associated with a greater than expected risk of total flap failure compared with use of a unilateral flap. This is of particular relevance due to the changing demographics of breast reconstruction, with a significant increase in the rate of bilateral mastectomies. ${ }^{2,3}$ Difficulties recruiting patients to randomized trials involving breast reconstruction, however, are well known, ${ }^{4}$ and well-conducted prospective studies likely will be the best way of informing the breast reconstruction literature.

The authors conducted a single-center prospective study during a 6-year period including 565 DIEP flaps in 468 women, including 371 unilateral (79.3\%) and 97 bilateral (20.7\%) reconstructions (194 flaps). In 81 patients (83.5\%), reconstruction was performed for either bi- or unilateral prophylactic mastectomies. Standardized outcome

(C) Society of Surgical Oncology 2017

First Received: 23 January 2017;

Published Online: 13 February 2017

C. E. Butler, MD

e-mail: cbutler@mdanderson.org measures were used. The primary outcome was any complication requiring return to the operating room within 30 days, and the secondary outcomes were revisional surgery, systemic complications, and hospital stay. ${ }^{5}$

Vein diameters also were collected based on coupler size, which although novel, must be acknowledged as a measurement of the diameter of the vein with the smallest caliber. Anterior abdominal wall perforator imaging was performed using duplex assessment. All flaps were performed by two senior surgeons, with preservation of the superficial inferior epigastric vein (SIEV) and preferential use of the internal mammary vessels.

Data were analyzed with the patient as the unit of analysis. The variables selected for logistic regression analysis were operative time, ischemic time, and laterality.

The complication rate, incidence of venous congestion, and total flap failure rate were significantly higher in the bilateral group. Venous flap congestion occurred for 8 patients $(8.25 \%)$ in the bilateral group and 10 patients (2.7\%) in the unilateral group (RR 3.1). Total flap loss occured in 5 patients (5.15\%) in the bilateral group and in 3 patient $(0.81 \%)$ in the unilateral group (RR 6.4). Notably, in the bilateral group, three of the flap failures occurred due to intraflap venous congestion and unilateral absence of the SIEV for salvage.

Interestingly, for each additional hour of operating beyond $4 \mathrm{~h}$, the odds of reoperation increased by $50 \%$, which may reflect intraoperative complications or that the case was more difficult than usual. Supporting this hypothesis, the odds of revisional surgery increased by $30 \%$ per hour over $4 \mathrm{~h}$ and twofold if a complication occurred. The most significant finding was that the RR of total flap loss was more than six times higher for bilateral reconstruction, with the majority of this difference attributable to the obligate need to use both sides of the 


\begin{tabular}{|c|c|c|c|c|c|c|c|c|c|}
\hline \multirow{3}{*}{ Study or Subgroup } & $\begin{array}{l}\text { Bilateral } \\
\text { Events }\end{array}$ & Total & \multicolumn{2}{|c|}{$\begin{array}{l}\text { Unilateral } \\
\text { Events Total }\end{array}$} & \multirow[t]{2}{*}{ Weight } & \multirow{2}{*}{$\begin{array}{c}\text { Risk Ratio } \\
\text { M-H, Random, 95\% Cl } \\
2.00[0.35,11.44]\end{array}$} & Year & \multicolumn{2}{|c|}{$\begin{array}{c}\text { Risk Ratio } \\
\mathrm{M}-\mathrm{H}, \text { Random, } 95 \% \mathrm{Cl}\end{array}$} \\
\hline & 2 & 32 & 3 & 96 & & & 2006 & & \\
\hline & 1 & 44 & 0 & 131 & $2.7 \%$ & $8.80[0.36,212.18]$ & 2007 & & \\
\hline Rao 2010 [9] & 11 & 114 & 6 & 233 & $29.3 \%$ & $3.75[1.42,9.88]$ & 2010 & & \\
\hline Schaverien 2011 [8] & 0 & 10 & 2 & 102 & $3.1 \%$ & $1.87[0.10,36.58]$ & 2011 & & \\
\hline McAllister 2016 [7] & 3 & 55 & 6 & 296 & $15.0 \%$ & $2.69[0.69,10.44]$ & 2016 & & \\
\hline Wade 2016 [1] & 5 & 97 & 3 & 371 & $13.8 \%$ & $6.37[1.55,26.21]$ & 2016 & & \\
\hline Beugels 2016 [6] & 6 & 104 & 9 & 322 & $27.0 \%$ & $2.06[0.75,5.66]$ & 2016 & & \\
\hline Total $(95 \% \mathrm{Cl})$ & & 456 & & 1551 & $100.0 \%$ & $3.09[1.83,5.22]$ & & & \\
\hline Total events & 28 & & 29 & & & & & & \\
\hline $\begin{array}{l}\text { Heterogeneity: } \mathrm{Tau}^{2}= \\
\text { Test for overall effect }\end{array}$ & $\begin{array}{l}0.00 ; \mathrm{Chi}^{2} \\
\mathrm{Z}=4.21\end{array}$ & $\begin{array}{l}=2.58 \\
P<0.0\end{array}$ & $\begin{array}{l}8, d f=6 \\
0001)\end{array}$ & $(P=0$. & $.86) ; I^{2}=$ & & & $\begin{array}{ccc}0.01 & 0.1 & 1 \\
\text { Favours bilateral DIEP }\end{array}$ & Favours unil \\
\hline
\end{tabular}

FIG. 1 Forest plot of outcomes in studies comparing uni- and bilateral deep inferior epigastric perforator (DIEP) flap reconstructions

abdomen and the inability for salvage in the face of intraflap venous congestion and no SIEV present.

To provide an up-to-date evaluation of the total flap failure risk for bilateral versus unilateral DIEP flap breast reconstruction, we searched Ovid EMBASE and MEDLINE to January 2017, and through data extraction and personal communication, we retrieved seven observational studies to inform a meta-analysis. ${ }^{1,6-11}$ (Figure 1). A pooled analysis showed an average total flap failure rate of $1.9 \%$ for unilateral flap failure (range $0-3.1 \%$ ) and $6.1 \%$ for bilateral reconstruction per patient (range 0-9.6\%; RR 3.1) (Fig. 1), similar to that previously reported. ${ }^{1}$ The total flap failure rate for the bilateral DIEP flap of 5.15\% reported by the authors is therefore in keeping with that reported at other high-volume centers. However, due to the very low rate for failure of unilateral reconstruction in their unit $(0.81 \%)$, the $\mathrm{RR}$ is more than twice that of other studies (RR 6.4 vs 3.1), and is an outlier that requires explanation.

It is now accepted that the venous drainage of abdominal flaps is of greater concern than arterial inflow. From an anatomophysiologic standpoint, great variation exists in how the venae comitantes of the deep inferior epigastric arterial perforators connect with the SIEV and its branches, and therefore in the ability to drain the flap effectively, independent of an additional anastomosis to the SIEV. These connections are broadly related to the position of the perforator in the flap with respect to the location of the SIEV. Both muscle-sparing transverse rectus abdominis muscle (TRAM) flaps and DIEP flaps based on multiple perforators may be associated with reduced rates of venous congestion in the absence of a suitable SIEV because of the ability to provide multiple routes for venous drainage. ${ }^{12,13}$ However, it is possible to select the perforators with direct connections between the deep and superficial venous systems based on preoperative computed tomography angiography (CTA) or magnetic resonance angiography (MRA) imaging. Appreciation of these connections allows for the best perforator or perforators to be selected for DIEP flap harvest, with a concomitant reduction in venous complications. ${ }^{13,14}$ Although the flaps are smaller in a bilateral reconstruction, this does not obviate the need for selection of suitable perforators to provide adequate venous outflow. ${ }^{15}$ The authors use duplex for their preoperative imaging, which does not allow for appreciation of these connections, and in light of the findings in this study, we recommend that they consider changing their presurgical imaging method to CTA or MRA to allow appreciation of the intraflap anatomy.

Of relevance, the authors also noted that despite operating with a team of two experienced surgeons, complications tracked with operation duration. This finding emphasizes the importance of considering fatigue as a major influence on operative success and the need for twoteam operating in more complex cases, as well as regular rest periods. The authors may find that using CTA or MRA also reduces surgeon stress and fatigue in bilateral cases, in which the surgeon has a full roadmap with which to plan the surgery, anticipate variations, and plan surgical lifeboats should they be required.

The authors should again be congratulated for their wellconducted prospective study that sheds further light on the unexpected and important finding of more than a double risk for total flap failure in bilateral DIEP flap breast reconstruction.

\section{REFERENCES}

1. Wormald JC, Wade RG, Figus A. The increased risk of adverse outcomes in bilateral deep inferior epigastric artery perforator flap breast reconstruction compared to unilateral reconstruction: a systematic review and meta-analysis. J Plast Reconstr Aesthet Surg. 2014;67:143-56.

2. Kummerow KL, Du L, Penson DF, Shyr Y, Hooks MA. Nationwide trends in mastectomy for early-stage breast cancer. JAMA Surg. 2015;150:9.

3. Jagsi R, Jiang J, Momoh AO, Alderman A, Giordano SH, Buchholz TA, et al. Trends and variation in use of breast reconstruction in patients with breast cancer undergoing mastectomy in the United States. J Clin Oncol. 2014;32;919. 
4. Winters ZE, Emson M, Griffin C, et al. Learning from the QUEST multicentre feasibility randomization trials in breast reconstruction after mastectomy. Br J Surg. 2015;102:45-56.

5. Potter S, Holcombe C, Ward JA, Blazeby JM. Development of a core outcome set for research and audit studies in reconstructive breast surgery. Br J Surg. 2015;102:1360-71.

6. Beugels J, Hoekstra LT, Tuinder SM, Heuts EM, van der Hulst RR, Piatkowski AA. Complications in unilateral versus bilateral deep inferior epigastric artery perforator flap breast reconstructions: a multicentre study. J Plast Reconstr Aesthet Surg. 2016;69:1291-8.

7. McAllister P, Teo I, Chin K, Makubate B, Alexander Munnoch D. Bilateral breast reconstruction with abdominal free flaps: a single-centre, single-surgeon retrospective review of 55 consecutive patients. Plast Surg Int. 2016;2016:1-9

8. Schaverien MV, Ludman CN, Neil-Dwyer J, Perks GB, Akhtar $\mathrm{N}$, Rodrigues JN, et al. Contrast-enhanced magnetic resonance angiography for preoperative imaging in DIEP flap breast reconstruction. Plast Reconstr Surg. 2011;128:56-62.

9. Rao SS, Parikh PM, Goldstein JA, Nahabedian MY. Unilateral failures in bilateral microvascular breast reconstruction. Plast Reconstr Surg. 2010;126:17-25.

10. Hofer SO, Damen TH, Mureau MA, Rakhorst HA, Roche NA. A critical review of perioperative complications in 175 free deep inferior epigastric perforator flap breast reconstructions. Ann Plast Surg. 2007;59:137-42.

11. Scheer AS, Novak CB, Neligan PC, Lipa JE. Complications associated with breast reconstruction using a perforator flap compared with a free TRAM flap. Ann Plast Surg. 2006; 56:355-8.

12. Kim DY, Lee TJ, Kim EK, Yun J, Eom JS. Intraoperative venous congestion in free transverse rectus abdominis musculocutaneous and deep inferior epigastric artery perforator flaps during breast reconstruction: a systematic review. Plast Surg Oakv. 2015;23:255-9. Review.

13. Schaverien MV, Ludman CN, Neil-Dwyer J, Perks AG, Raurell A, Rasheed T, et al. Relationship between venous congestion and intraflap venous anatomy in DIEP flaps using contrast-enhanced magnetic resonance angiography. Plast Reconstr Surg. 2010; 126:385-92.

14. Wagels M, Pillay R, Saylor A, Vrtik L, Senewiratne S. Predicting venous insufficiency in flaps raised on the deep inferior epigastric system using computed tomography (CT) angiography. J Plast Reconstr Aesthet Surg. 2015;68:e200-2.

15. Rubino C, Ramakrishnan V, Figus A, Bulla A, Coscia V, Cavazzuti MA. Flap size/flow rate relationship in perforator flaps and its importance in DIEAP flap drainage. $J$ Plast Reconstr Aesthet Surg. 2009;62:1666-70. 